\title{
Chemical Composition and Larvicidal Activity of Flower Extracts from Clitoria ternatea against Aedes (Diptera: Culicidae)
}

\author{
Darvin R. Ravindran, ${ }^{1}$ Madhuri Bharathithasan, ${ }^{1}$ Patmani Ramaiah, ${ }^{2}$ \\ Mohd Sukhairi Mat Rasat, ${ }^{3}$ Dinesh Rajendran, ${ }^{4,5}$ Shakila Srikumar, ${ }^{1}$ Intan H. Ishak, ${ }^{4,5}$ \\ Abd Rahman Said, ${ }^{1}$ Rajiv Ravi $\mathbb{D}^{6},{ }^{6}$ and Mohamad Faiz Mohd Amin $\mathbb{D}^{7}$ \\ ${ }^{1}$ Faculty of Medicine, Quest International University Perak, Jalan Hj, Eusoff Housing Trust, Ipoh 30250, Perak, Malaysia \\ ${ }^{2}$ Faculty of Medicine, Universiti Kuala Lumpur Royal College of Medicine Perak (UniKL RCMP), 30450 Ipoh, Perak, Malaysia \\ ${ }^{3}$ Faculty of Bioengineering and Technology, Universiti Malaysia Kelantan, Jeli Campus, Jeli, Kelantan, Malaysia \\ ${ }^{4}$ School of Biological Sciences, Universiti Sains Malaysia, Minden, Penang, Malaysia \\ ${ }^{5}$ Vector Control Research Unit, School of Biological Sciences, Universiti Sains Malaysia, Minden, Penang, Malaysia \\ ${ }^{6}$ School of Biological Sciences, Faculty of Science and Technology, Quest International University Perak, \\ Jalan Raja Permaisuri Bainun, Ipoh 30250, Perak, Malaysia \\ ${ }^{7}$ Faculty of Earth Science, Universiti Malaysia Kelantan, Jeli Campus, Jeli, Kelantan, Malaysia
}

Correspondence should be addressed to Rajiv Ravi; rajiv_ravi86@yahoo.com and Mohamad Faiz Mohd Amin; mohamadfaiz@umk.edu.my

Received 17 June 2020; Accepted 15 September 2020; Published 1 October 2020

Academic Editor: Ioannis G. Roussis

Copyright (c) 2020 Darvin R. Ravindran et al. This is an open access article distributed under the Creative Commons Attribution License, which permits unrestricted use, distribution, and reproduction in any medium, provided the original work is properly cited.

\footnotetext{
Mosquitoes have always been a human health threat; the major global health problems caused by them are malaria, dengue fever, yellow fever, and Zika as well as several other vector-borne outbreaks. The major problems in controlling these vectors borne diseases are related to resistance to eradication measures. Different classes of insecticides used for controlling public health have raised the concern of resistant problems with mosquitoes and environmental pollution caused by the control measures. Thus, a search for alternative natural compounds is necessary for solving the insecticidal resistance problem using pesticides in the larval stage of vector development as well as creating a chemical-free environment for a healthy society. Hence, the major focus of this study is to identify the larvicidal mechanisms, metabolite, antioxidants, and chemical compounds and elucidate their structures from C. ternatea flower and to test their efficacies against early 4th instar larvae of Aedes aegypti and Aedes albopictus. Clitoria ternatea flowers were collected from the garden of the Faculty of Medicine in International Quest University, Ipoh, Perak, and thence used for crude extraction. Further on, the metabolite test, antioxidant test, and chromatography techniques were conducted to identify the chemical composition of extracts and their chemical structures were identified using GCMS-QP2010 Ultra (Shimadzu). Next, the extracts were evaluated against the early 4th instar larvae of Aedes mosquito vectors following the WHO procedures for larval bioassays. The larvicidal activity of Clitoria ternatea flower extracts evidently affected the early 4 th instar larvae of Aedes mosquito vectors. The highest larvicidal activity was observed against the early 4th instar larvae of Aedes aegypti with the LC50 and LC95 values of 1056 and $2491 \mathrm{mg} / \mathrm{L}$, respectively. Meanwhile, the larvae bioassay test for Aedes albopictus recorded the LC50 and LC95 values of 1425 and $2753 \mathrm{mg} / \mathrm{L}$. Moreover, the results for nontarget organism test on guppy fish, Poecilia reticulata, showed no mortalities with flower extracts at $2500 \mathrm{mg} / \mathrm{L}$, hence posing no toxic effects on fish. In this study, we have found a total of 16 chemical compounds and 6 chemical compounds have been reported to possess direct insecticidal, larvicidal, and pupicidal effects. Six chemicals with insecticidal properties were found to be glycerin, 2-hydroxygamma-butyrolactone, neophytadiene, $n$-hexadecanoic acid, cis-vaccenic acid, and octadecanoic acid with a total of $28.7 \%$ efficacy. Clitoria ternatea flower extracts also showed different types of phenols such as anthocyanins, flavonoids, and tannins. Our findings showed that the crude extract of Clitoria ternatea flower bioactive molecules is effective and may be developed as biolarvicide for Aedes mosquito vector control. Furthermore, this study also provided a baseline understanding for future research work in the field of applications of Clitoria ternatea flower extracts for their long-term effects on human health such as a food additive, antioxidant, and cosmetic.
} 


\section{Introduction}

Mosquitoes have always been a human health threat from eons; the major health problems caused by them are malaria, dengue fever, yellow fever, and Zika as well as several other vector-borne diseases. Based on World Health Organization [1], western Pacific region, northern hemisphere reports on January 2020 dengue updates recorded were as follows: Cambodia with a higher average of 1239 cases weekly compared to the period of 2019; Malaysia with lower $4.2 \%$ decrease weekly as 2604 cases with 9 deaths compared to the period of 2019; Philippines with 2778 cases with 10 deaths in 2020; Singapore with 2508 cases, higher compared to the period of 2019; Vietnam with 1282 weekly cases at 2020. In the southern hemisphere, Australia has recorded 78 dengue cases since the beginning of 2020 till 26 February 2020, which is lower compared to the period of 2019 [1]. Thus, dengue cases are inevitable in human community and there are many factors contributing towards this global issue.

In the current situation, only physical and chemical methods are being used to control mosquito-borne diseases. Physical methods such as mosquito bed nets, mosquito window nets at homes, and electrical mosquito rackets are only temporary solutions [2]. Besides that, the chemicals used for vector control such as temephos and pyrethroids are more well-known with some insecticides resistant challenges [2]. Chemical insecticides are synthesized chemically based on single bioactive compounds with reference to structurally related plant compounds, which lead to the current resistance problem for all mosquitocide classes [2-5]. Only one single chemical compound can be synthesized at a time due to its high toxicity effects and the multiple plant biochemical compounds are more stable and lower in toxicity due to their synergetic effects under natural conditions. Additionally, Ravi et al. [4] supported the concepts of botany control mechanisms as a simple and sustainable method compared to the conventional insecticides in use.

Unlike current synthetic or chemical insecticides, the advantages of plant-based insecticides are their compositions of natural blends of multiple chemical compounds that may act synergistically on both physiological and behavioral processes of mosquitoes [2-6]. Thus, botanicalbased insecticides are an alternative and accurate solution against dengue vectors of Aedes aegypti and Aedes albopictus.

In tune with the concept of a safer alternative, Clitoria ternatea plant has the potential as a bioinsecticide to solve the problems of resistance from a single-based chemical compound. Clitoria ternatea is a well-known flower in Asian countries such as Malaysia, Thailand, Philippine, India, and China and widely used in Ayurveda and Chinese medicine [7]. Additionally, Malaysians use the extract of the flower as a food coloring to prepare a popular dish called Nasi Kerabu and Indians from the state of Kerala region consume this plant as a vegetable on a daily basis [7]. The potential compounds of this plant are prevalent in the form of polyphenols, triterpenoids, flavonoids, glycosides, anthocyanins, tannins, and steroids [8]. To date, only one study, Mathew et al. [9], has reported the basic use of C. ternatea as an Aedes aegypti and Aedes stephensi mosquito larvicidal but none on Ae. albopictus. According to Mathew et al. [9], the methanolic extract of C. ternatea showed larvicidal effectiveness; however, no mechanisms of larvicidal were explained and hence suggested improvements on further investigations pertaining to the active principles of the chemical compounds responsible for larvicidal activities. Thus, within this expansion of framework, this seems to be the first study to elucidate larvicidal mechanism, metabolite, antioxidant, and chemical compound identifications from C. ternatea flower which may be responsible for Aedes larvicidal activities. The objective of this study is to identify the larvicidal mechanism, metabolite, antioxidant, chemical compounds, and the structure of $C$. ternatea flower and to test its efficacies against the early 4 th instar larvae of Aedes aegypti and Aedes albopictus.

\section{Materials and Methods}

2.1. Statement for Experimental Protocols. All experimental protocols mentioned in this paper were in accordance with larval susceptibility test method guidelines by the World Health Organization (WHO).

2.2. Plant Materials. Clitoria ternatea used for this study was authenticated by the Herbarium of the University of Malaya with the herbarium voucher number KLU60080. Clitoria ternatea flowers (Figure 1) were collected from the garden of the Faculty of Medicine in International Quest University, Ipoh, Perak. The petals of $C$. ternatea were washed in running tap water to remove adhered debris and soil particles and washed again with distilled water and dried in hot air oven at $70^{\circ} \mathrm{C}$ until the petals were completely dry [10]. The dried petals were ground into fine powder by using a laboratory grinder and stored in a vacuum-tight container for further usage.

2.3. Aqueous Extraction. Aqueous extraction was performed by maceration using $250 \mathrm{ml}$ distilled water and $50 \mathrm{~g}$ of the powdered C. ternatea flowers petal. They were mixed in a $500 \mathrm{ml}$ beaker and stored in a dark area for an hour. Then, the extract was filtered using cotton wool and filter paper. The final volumes were stored in a universal bottle and maintained at $4^{\circ} \mathrm{C}$ to $6^{\circ} \mathrm{C}[10]$.

2.4. Methanol Extraction. Methanol extraction was performed in three different concentrations of 50\%, 70\%, and $95 \%$. A mixture of $5 \mathrm{~g}$ powdered C. ternatea flower petals and $100 \mathrm{ml}$ of respective concentration of methanol was prepared in three separate Scott bottles and covered with aluminum foil to avoid exposure to light. Later, the bottles 


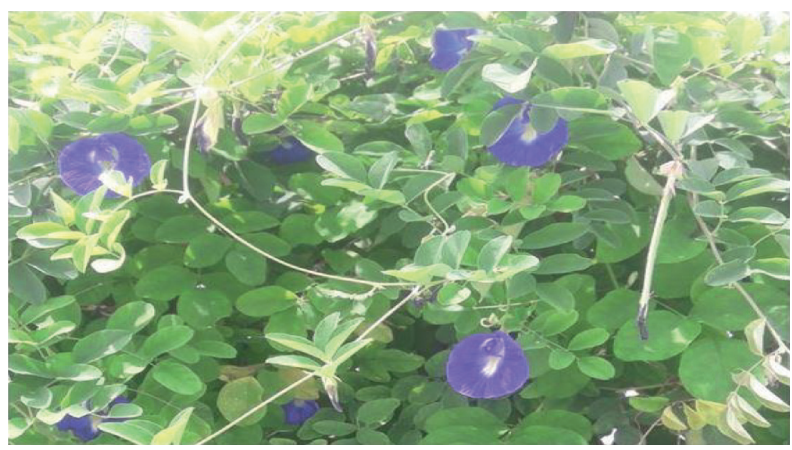

FIgure 1: Picture of Clitoria ternatea flower from the field.

were kept overnight in the orbital shaker for the maceration process. After 24 hours, the extract was filtered using cotton wool and filter paper by vacuum filtration method. Subsequently, they were concentrated using rotary evaporator at the temperature of $45^{\circ} \mathrm{C}$. Finally, the remained concentrated amount of extract was stored in a universal bottle and maintained at $4^{\circ} \mathrm{C}$ to $6^{\circ} \mathrm{C}[4,11]$.

2.5. Ethanol Extraction. Ethanol extraction was prepared in three different concentrations similar to methanol extractions of $50 \%, 70 \%$, and $95 \%$. Maceration process was performed using $5 \mathrm{~g}$ of powdered $C$. ternatea flower petals and $100 \mathrm{ml}$ of respective concentrations of ethanol, mixed in three separate Scott bottles, then covered with aluminum foil to avoid exposure to light. Later, the bottles were kept at room temperature for 24 hours. The following day, all the extracts were filtered using cotton wool and filter paper by vacuum filtration method. Next, they were concentrated using rotary evaporator with the temperature at $60^{\circ} \mathrm{C}$. Finally, the concentrated extracts were stored in a universal bottle and maintained at $4^{\circ} \mathrm{C}$ to $6^{\circ} \mathrm{C}[11]$.

2.6. Petroleum Ether Extraction. Petroleum ether extraction was done with $5 \mathrm{~g}$ of fresh flowers; they were cut into small pieces and soaked in a Scott bottle with $50 \mathrm{ml}$ of petroleum ether for 48 hours. Later, the extract was filtered out using filter paper and transferred to a universal bottle and stored at $4^{\circ} \mathrm{C}$ to $6^{\circ} \mathrm{C}[12]$.

2.7. Ethyl Acetate Extraction. Ethyl acetate extraction was done with $5 \mathrm{~g}$ of powdered $C$. ternatea flower petals and $100 \mathrm{ml}$ of ethyl acetate in a Scott bottle and then covered with aluminum foil to avoid exposure to light. Then, the bottle was kept at room temperature for 48 hours and after 48 hours, the extract was filtered out using cotton wool and filter paper. Finally, they were stored in a universal bottle and maintained at $4^{\circ} \mathrm{C}$ to $6^{\circ} \mathrm{C}[13]$.

2.8. Test for Flavonoid. Flavonoids identification was determined with two different chemical tests for all nine extracts; $1 \mathrm{ml}$ of $C$. ternatea extracts was added to a test tube followed by a few drops of $\mathrm{FeCl}_{3}$; the color changes were observed. The second confirmation test for the presence of flavonoids was done in another test tube by adding $1 \mathrm{ml}$ of crude extract and few drops of $5 \%$ of $\mathrm{AlCl}_{3}$ solution and the color changes were observed [14].

2.9. Test for Anthocyanins. Anthocyanins identification was determined with two different chemical tests for all nine extracts. First, $1 \mathrm{ml}$ of crude extract was added to a test tube followed by $2 \mathrm{ml}$ of $\mathrm{HCl}$ and then heated for $5 \mathrm{~min}$ at $100^{\circ} \mathrm{C}$, and the color changes were observed. For the second test, $1 \mathrm{ml}$ of crude extract was added to a test tube followed by $2 \mathrm{ml}$ of $\mathrm{NaOH}$, and then the color changes were observed [14].

2.10. Test for Tannins. Tannins were determined with a chemical test for all nine extracts; $1 \mathrm{ml}$ of crude extract was added to a test tube followed by a few drops of $\mathrm{FeCl}_{3}$. Then the color changes were observed [14].

2.11. Test for Polyphenols. A UV-visible spectrophotometer was used to evaluate the concentrations of polyphenols present in each extract, the absorbance of which was measured at $725 \mathrm{~nm}$ wavelength. All the measurements were performed in triplicate for each sample [13].

2.12. Paper Chromatography. Paper chromatography was used to study the fractions of the components. Chromatography paper was used to study the fractions of the extracts by placing $10 \mu \mathrm{L}$ of crude extract and allowing them to dry completely before immersing in the solvent. The solvent used in this process was the same solvent that was used for the extraction processes such as the aqueous, 50\% methanol, $70 \%$ methanol, 95\% methanol, 50\% ethanol, 70\% ethanol, 95\% ethanol, petroleum ether, and ethyl acetate. Subsequently, the Rf values were calculated and the results interpreted comparing with the controls [15].

2.13. Thin-Layer Chromatography. Thin-layer chromatography is also a method to study the components based on the principle of fractionation. The solvent used for thin-layer chromatography is a mixture of methanol and chloroform and this process was done in a specific TLC tank. First, the TLC gel was applied on the plate and was spotted by all the 
crude extracts and allowed to dry for a few minutes and then the gel plate was placed into the tank to immerse with the solvent. Lastly, $1 \% \mathrm{FeCl}_{3}$ was sprayed on the gel plate to identify the spots and fix the spots and $\mathrm{Rf}$ values were calculated based on the measurements and the results interpreted comparing with the control spots [9].

2.14. Antioxidant Activity. Based on Fu et al. [16], antioxidant scavenging activity of $C$. ternate petals extractions was measured using DPPH solvent. To conduct the study, a 96well plate was used to mix the extract with the DPPH solvents and other controls. Later, the plate was covered with aluminum foil and left in a dark area for 30 minutes. During this test, ascorbic acid was used as the positive control and Tris- $\mathrm{HCl} / \mathrm{L}$ buffer was used as the negative control; lastly, the color changes were observed, and OD was read using the ELISA reader at $517 \mathrm{~nm}$. The scavenging activity of DPPH radicals was calculated using the following equation:

$$
\text { scavenging activity }(\%)=\left[\frac{(\text { negative control }- \text { sample })}{(\text { negative control }- \text { positive control })}\right] \times 100
$$

2.15. GC-MS Analysis. The GC-MS analysis was done only with the methanol $\left(\mathrm{CH}_{3} \mathrm{OH}\right)$ solvent extract and was used to determine the compounds with the analysis performed on a GCMS-QP2010 Ultra Shimadzu. The reason for only choosing methanol $\left(\mathrm{CH}_{3} \mathrm{OH}\right)$ solvent is due to its extract's best efficacies against Aedes larvae, as published before in several plant-based larvicidal papers [2-5]. The GCMS-QP2010 Ultra Shimadzu system was fitted with Rtx-5MS capillary column, the measurement of $30 \mathrm{~m} \times 0.25 \mathrm{~mm}$ inner diameter, and $\times 0.25 \mu \mathrm{m}$ film thicknesses and the maximum temperature that can be used is $370^{\circ} \mathrm{C}$, coupled with a QP2010 Ultra Shimadzu MS. Ultra-high-purity helium was used as carrier gas at a constant flow rate of $1.0 \mathrm{~mL} / \mathrm{min}$. The injection, transfer line, and ion source temperatures were all at $280^{\circ} \mathrm{C}$. The oven temperature was programmed from $80^{\circ} \mathrm{C}$ and it was held for $2 \mathrm{~min}$ and raised to $280^{\circ} \mathrm{C}$ at a rate of $3^{\circ} \mathrm{C} / \mathrm{min}$. The crude samples were diluted with an appropriate solvent and filtered. The particlefree diluted crude extracts about $1 \mu \mathrm{L}$ were taken in a syringe and injected into an injector with a split ratio of $10: 1$. All data were obtained by collecting the full-scan mass spectra within the scan range of 40-550 amu. The percentage composition of the crude extract constituents was expressed as the percentage by peak area. The identification and characterization of chemical compounds in various crude extracts were based on the GC retention time $[2,4]$.

2.16. Larvae Rearing. The eggs of Aedes were obtained from Vector Control Research Unit (VCRU) at Universiti Sains Malaysia (USM), Penang, Malaysia. We followed the method used by WHO $[2-5,17]$ in larvae rearing. The eggs were hatched in dechlorinated water for 24 hours and were maintained at $25^{\circ} \mathrm{C}$ to $30^{\circ} \mathrm{C}$ (room temperature), $\mathrm{pH}$ of 6.95 to 7.03 , and relative humidity of $80 \pm 10 \%$ and dissolved oxygen from 5.5 to $6.1 \mathrm{mg} / \mathrm{L}$ in the laboratory. After five days, the early 4th instar larvae will be used for the bioassay test.

2.17. Larvicidal Bioassay. Larvicidal bioassays were performed in accordance with the standard World Health Organization [17]. Bioassays were carried out using 25 each of Aedes aegypti and Aedes albopictus early 4th instar larvae (homogeneous population consisting $5 \mathrm{~mm}$ to $6 \mathrm{~mm}$ in body length). The bioassays were replicated four times using 25 larvae for each concentration with methanol $\left(\mathrm{CH}_{3} \mathrm{OH}\right)$ as solvent control. The methanol $\left(\mathrm{CH}_{3} \mathrm{OH}\right)$ solvent extraction was chosen for larvicidal in this current study due to previous studies by Ravi et al. [2-5], which showed that methanol $\left(\mathrm{CH}_{3} \mathrm{OH}\right)$ solvent had the best larvicidal effects on Aedes. During the larvae testing period, fish meal was provided. Initially, before selecting the accurate testing dose, all the larvae were subjected to a wide range of test concentrations. This step is necessary to determine the range of extract solution for larvicidal activities $[2,4,5]$. In this study, seven concentrations ranging from $500 \mathrm{mg} / \mathrm{L}$ to $2500 \mathrm{mg} / \mathrm{L}$, yielding between 0 and $100 \%$ mortality in 24 hours of exposure, were selected as test concentrations. Control solutions were prepared with $1 \mathrm{ml}$ of distilled water and $10 \%$ of respective methanol solvent during each experimental replicate $[2,4,5]$. The reason for using solvent control is to ensure that all test replicates are identical to plant extract solutions and to ensure that mortality results were not due to its solvents $[2,4,5]$. Experiments were conducted at room temperature $28 \pm 2^{\circ} \mathrm{C}$ and larvae mortalities were recorded at intervals of 24 hours and 48 hours [14]. Immobilization and total absence of movement from the larvae, even aftertouch, are the endpoint of bioassay $[2,4,5]$. The data were analyzed by using probit analysis in IBM SPSS Statistics 24.

2.18. Morphological View. Aedes aegypti early 4th instar larvae were observed under the optical microscope (Leica, USA), at magnification 40-400x [4].

2.19. Nontargeted Organism Test. Guppy fish, Poecilia reticulata, a total of ten fish in three replicates with $1.20 \mathrm{~g}$ mean weight and $3.5 \mathrm{~cm}$ mean length, were used in this test (acclimatization period of 12 days in laboratory conditions before the start of the experiment). Each treatment group 
has been tested with larvicidal $\mathrm{LC}_{95}$ plant extract concentration dissolved in $2000 \mathrm{~mL}$ dechlorinated water. A control group has also been set with only $2000 \mathrm{~mL}$ of nonchlorinetreated water. The tests were performed for 24 hours with observations made at first 10 minutes and then 1, 2, 3, 6, and 24 hours. The mortality and observable abnormalities of fish were recorded. Test conditions of water such as $\mathrm{pH}$, water temperature, and dissolved oxygen were recorded during the start and end of the experiment [4].

\section{Results}

3.1. Metabolite Study. Based on the S1 and S2 (refer to supplementary file (available here)), the absorbance showed a higher presence of anthocyanin, flavonoids, and tannins in the C. ternatea flower extracts of $95 \%$ methanol compared to other extractions.

3.2. Paper Chromatography. All the values in $\mathrm{S} 3$ (refer to supplementary file) show the three-retention factor, $\mathrm{Rf}$ values present in $C$. ternatea flower extracts in all the solvents used for the extraction process. The use of methanol solvent showed higher retention factor, $\mathrm{Rf}$ values compared to other solvents.

3.3. Thin-Layer Chromatography. All the values in S4 (refer to supplementary file) show the three-retention factor, Rf values present in $C$. ternatea flower extracts in all the solvents used for the extraction process. The use of methanol and ethanol solvent showed approximately similar retention factor, Rf values.

3.4. Antioxidant Activity. 2,2-Diphenyl-1-picrylhydrazyl (DPPH) was used to identify the presence of antioxidant property in each extract. Based on S5 (refer to supplementary file (available here)), the graph shows the extracts with high antioxidant property and low antioxidant property. The extract that carried the highest antioxidant property was aqueous in nature.

3.5. GC-MS Analysis and Identification of Compounds. GC-MS analysis of methanol solvent extracts of C. ternatea flower showed 16 peaks which indicate the presence of 16 phytochemical compounds S6 (refer to supplementary file). Comparing the mass spectra of the constituents with the NIST 08 library, 16 compounds were characterized and identified (Table 1). The major three chemical compounds in the extracts showing the highest peaks were acetic acid, 1-(2methyltetrazol-5-yl) ethenyl ester (16.5\%), 4H-pyran-4-one, 2,3-dihydro-3,5-dihydroxy-6-methy (13.9\%), and di-glyceraldehyde dimer (12.4\%). The attached S6 (refer to supplementary file) contains the NIST 08 library search for chemical compound structures and details.

3.6. Larvicidal Bioassay. The bioassay testing from methanol solvent extracts of C. ternatea flower was tested at $300 \mathrm{mg} / \mathrm{L}$, $500 \mathrm{mg} / \mathrm{L}, 1000 \mathrm{mg} / \mathrm{L}, 1500 \mathrm{mg} / \mathrm{L}, 1700 \mathrm{mg} / \mathrm{L}, 2000 \mathrm{mg} / \mathrm{L}$, and $2500 \mathrm{mg} / \mathrm{L}$. The entire larvae bioassay test with C. ternatea flower extracts showed a significant increase in mortality percentage with the increase of concentration. On comparing the tested flower extracts, maximum larvicidal activity was observed to be against early 4th instar larvae of Aedes aegypti with the LC50 and LC95 values of 1056 and $2491 \mathrm{mg} / \mathrm{L}$, respectively (Table 2). Meanwhile, the larvae bioassay test for Aedes albopictus recorded the LC50 and LC95 values of 1425 and $2753 \mathrm{mg} / \mathrm{L}$ (Table 2). Figure 2 shows the graphical representation of larvae mortality rate between Aedes aegypti and Aedes albopictus. Finally, the results for nontarget organism test on guppy fish, Poecilia reticulata, showed no mortalities with plant extracts at $2500 \mathrm{mg} / \mathrm{L}$, posing no toxic effects on this fish (Figure 3). The 95\% confidence limits LC50 (95\% CI) and LC95 (95\% CI), chisquare, and degree of freedom ( $d f$ ) values were also calculated (Table 2). In the control assay, there was no significant mortality.

3.7. Morphological View. The morphological view from Figures 4(a) and 4(b) is indicating the presence of $C$. ternatea flower extracts in the midgut content by dark greenish color of extracts.

\section{Discussion}

The results of this study have shown that the phytochemical compounds extracted from C. ternatea flower may have innovative and integrated property of a bio insecticidal agent. Thus, this study intends to highlight the role of the extract as an alternative control measure against Aedes when compared to the synthetic insecticides. Additionally, C. ternatea flower extracts may be more effective than single-based active compound due to their active ingredients' synergisms which may be effective in managing resistant population of mosquitoes. In this study, we have found a total of 16 chemical compounds and 6 chemical compounds have been reported to possess direct insecticidal, larvicidal, and pupicidal effects. The six chemicals used for their insecticidal properties in previous studies were glycerin, 2-hydroxy-gamma-butyrolactone, neophytadiene, n-hexadecanoic acid, cis-vaccenic acid, and octadecanoic acid constituting a total of $28.7 \%$. All these chemical components have direct larvicidal activity and there are many more compounds which may act synergistically in the larvicidal activity. Similarly, Ravi et al. $[2,4]$ have also discussed the synergetic effects of multiple chemical compounds from plant extract against Aedes larvae.

A previous study by Mathew et al. [9] on Clitoria ternatea extracts did not show the mechanism of larvicidal activity. However, to elucidate the effects of larvicidal mechanisms, this current study has shown the effect of the extract on the midgut after ingestion as shown in the morphological picture (Figures 4(a) and 4(b). The ingested plant extracts shown in Figures 4(a) and 4(b) were quite similar to the previous study done with Azolla pinnata plant extracts (green color) in the larvae midgut content after 24 hours of ingestion [4]. Thus, it 
TABle 1: Chemical compounds for Clitoria ternatea flower.

\begin{tabular}{|c|c|c|c|c|c|}
\hline $\mathrm{S} / \mathrm{N}$ & RT & Area & Area (\%) & Compound name & Activity \\
\hline 1 & 4.256 & 42912 & 9.631 & Glycerin & Pupicidal and larvicidal [18] \\
\hline 2 & 4.65 & 9713 & 2.18 & 2,4-Dihydroxy-2,5-dimethyl-3(2H)-furan-3-one & Anthelminthic [19] \\
\hline 3 & 4.823 & 21616 & 4.851 & 2-Hydroxy-gamma-butyrolactone & Insecticidal metabolite $[20,21]$ \\
\hline 4 & 6.927 & 73492 & 16.494 & Acetic acid, 1-(2-methyltetrazol-5-yl)ethenyl ester & Agricultural [22] \\
\hline 5 & 8.602 & 55658 & 12.491 & dl-Glyceraldehyde dimer & Antioxidant [23] \\
\hline 6 & 8.84 & 15893 & 3.567 & Alpha-amino-gamma-butyrolactone & Antioxidant and cytotoxic [24] \\
\hline 7 & 9.151 & 61940 & 13.901 & $\begin{array}{l}\text { 4H-pyran-4-one, 2,3-dihydro-3,5-dihydroxy-6- } \\
\text { methy }\end{array}$ & Antioxidant [25] \\
\hline 8 & 12.709 & 46623 & 10.463 & 1,2,3-Propanetriol, monoacetate & Antimicrobial [26] \\
\hline 9 & 14.048 & 16670 & 3.741 & $\begin{array}{c}\text { 1,2-Dioxolan-3-one, 5-ethyl-5-methyl-4- } \\
\text { methylene- }\end{array}$ & Antioxidant [27] \\
\hline 10 & 20.099 & 3546 & 0.796 & 4-Ethylamino- $n$-butylamine & $\begin{array}{l}\text { Herbicidal and insect lighting coating material } \\
\qquad[28,29]\end{array}$ \\
\hline 11 & 20.22 & 30010 & 6.735 & $\begin{array}{l}\text { 1,6-Anhydro-2,4-dideoxy-beta- D-ribo- } \\
\text { hexopyranose }\end{array}$ & Pesticidal [30] \\
\hline 12 & 30.899 & 3872 & 0.869 & 2-Propenoic acid, tridecyl ester & Antifungal [31] \\
\hline 13 & 36.132 & 3771 & 0.846 & Neophytadiene & Larvicidal $[4]$ \\
\hline 14 & 40.342 & 31374 & 7.041 & $n$-Hexadecanoic acid & Larvicidal $[2,4]$ \\
\hline 15 & 45.991 & 26925 & 6.043 & cis-Vaccenic acid & Larvicidal [32] \\
\hline 16 & 46.693 & 1566 & 0.351 & Octadecanoic acid & Larvicidal $[2,4]$ \\
\hline
\end{tabular}

S/N: signal noise; RT: retention time.

TABLE 2: Larvicidal activity of Clitoria ternatea flower extracts against early 4th instar larvae of Aedes aegypti and Aedes albopictus.

\begin{tabular}{lccccc}
\hline Larvae & $\mathrm{LC}_{50}(\mathrm{mg} / \mathrm{L})(95 \% \mathrm{LCL}-\mathrm{UCL})$ & LC $_{95}(\mathrm{mg} / \mathrm{L})(95 \% \mathrm{LCL}-\mathrm{UCL})$ & $\chi^{2}$ & $d f$ \\
\hline A. aegypti & $1056(981-1121) Y=-14.142+4.722 X$ & $2491(2094-2641) Y=-14.142+4.722 X$ & $30^{*}$ & 22 & 0.667 \\
A. albopictus & $1425(1352-1491) Y=-19.682+6.282 X$ & $2753(2374-2881) Y=-19.682+6.282 X$ & $30^{*}$ & 22 & 0.882 \\
\hline
\end{tabular}

$N_{a}$ : total number of mosquitoes larvae used, $n=25$ each with 4 replicates; LC50: lethal concentration 50\% mortality; LC95: lethal concentration $95 \%$ mortality; LCL: lower confidence limits; UCL: upper confidence limits; $\chi^{2}$ : Pearson chi-square; $d$ f: degrees of freedom; $R$ : Pearson's $R$ (note: chi-square values with an asterisk are significant $(P<0.05))$.

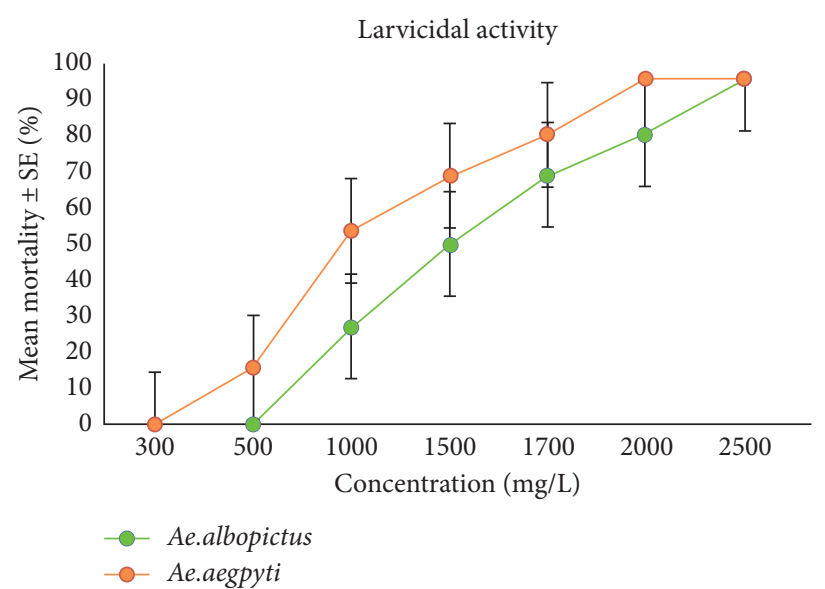

FIgUre 2: Comparison of larvae mortality rate between Aedes aegypti and Aedes albopictus for various Clitoria ternatea flower extract concentrations.

can be congruently observed that the C. ternatea extract ingestion mechanism was used in the killing effect of Aedes larvae. As per the results shown by the C. ternatea extract on the guts of larvae, the potential commercialization of this extract would be done using liquid-based techniques. An example of a similar possible commercial application done in the past was "Dalmatian Powder," dissolved in liquid for its application [33]. Additionally, the storage condition of the crude extract in this study was at $-4^{\circ} \mathrm{C}$ before its application under room temperature. Similarly, Ravi et al. [4] have prevented the degradation of crude extract by storing it at $-4^{\circ} \mathrm{C}$ before its application. 


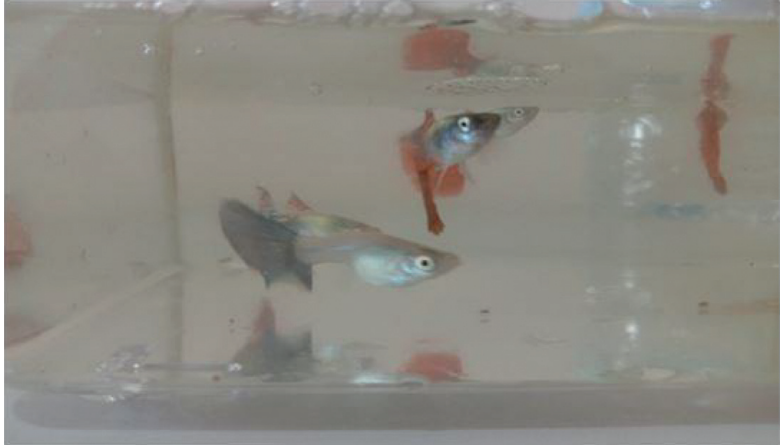

Figure 3: Guppy fish, Poecilia reticulata, toxicity test with Clitoria ternatea.
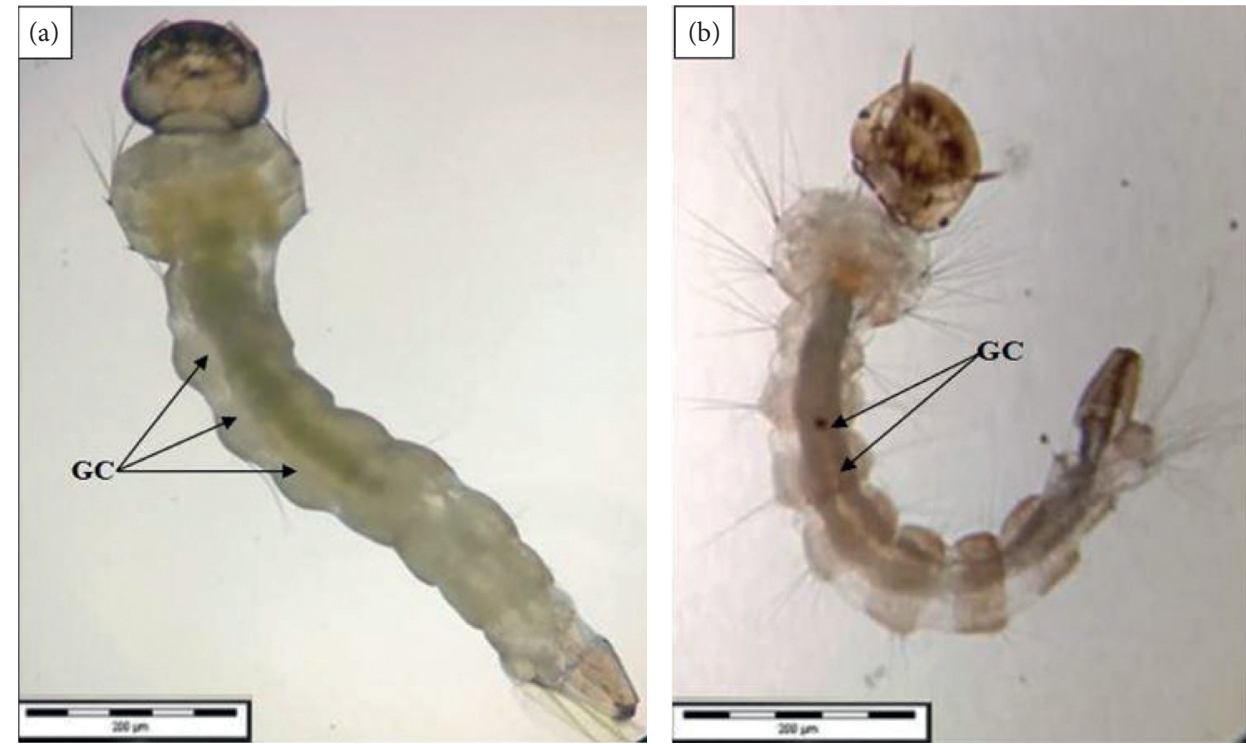

Figure 4: Morphological midgut content induced by Clitoria ternatea. (a) Midgut content view in larvae of Aedes aegypti. (b) Midgut content view in larvae of Aedes albopictus. Note. Arrows indicate the plant extracts (dark greenish color); GC: gut content (after 24 hours).

The residual activity of $C$. ternatea flower extract showed up to 48 hours in water. Moreover, Ullah et al. [34] recorded that there are five different plant species with residual activities against Culex quinquefasciatus up to 72 hours upon their application. Elsewhere, a study on Azolla pinnata extract has suggested that 48 hours of residual activity in water and plant-based applications was much shorter in their residual effects compared to synthetic pesticides [4]. Thus, it can be concluded that plant-based insecticides possess lesser residual activity compared to synthetic chemicals. Additionally, the C. ternatea plant extracts did not possess any toxic effects on fish. According to Pereira and Oliveira [35], Poecilia reticulata has important potential effects to predate Aedes aegypti larvae and this will help to eliminate the breeding ground of larvae. Thus, without the toxic effects of $C$. ternatea extracts on Poecilia reticulate, we could integrate both applications using C. ternatea and fish to control Aedes larvae. In addition to that, the toxicity results in this current study were also similar to the previous study based on Azolla pinnata plant [2,4]. Thus, the use of C. ternatea extract is not toxic for the environment and it is safer to be applied compared to chemical application in controlling Aedes larvae.

In addition to that, the metabolite study of $C$. ternatea extracts showed different types of phenols such as anthocyanin, flavonoids, and tannins. Anthocyanin, flavonoids, and tannins were present in both methanol and ethanol extracts of $C$. ternatea compared to other extracts (Table 1). Divya et al. [14] reported similar findings on Clitoria ternatea blue and white flowered leaves which recorded the highest polyphenol isolation using methanol extraction techniques. Moreover, this was further proven with thinlayer chromatography and paper chromatography techniques, whereby all the extracts were found to have three spots upon fixing with ferric chloride $\left(\mathrm{FeCl}_{3}\right)$. Concurrently, Sunita et al. [36] have also reported the same results with medicinal plant using ferric chloride $\left(\mathrm{FeCl}_{3}\right)$ to identify only phenolic compounds on chromatography paper. Finally, the antioxidant test for $C$. ternatea flower extracts showed that aqueous extract has the highest antioxidant property compared to other extraction methods. The aqueous extract was found to have high antioxidant because water extract 
can absorb antioxidant compound better than chemicals [37].

Thus, it can be concluded that $C$. ternatea flower extractbased insecticides may possess lesser residual activity compared to synthetic chemicals and contain multiple natural chemical compounds which may solve the singlebased insecticide-resistant problems. Finally, although C. ternatea flower extracts may be used as bio-larvicides, future testing would have to be conducted to validate their long-term effects on human health and other organisms in the environment.

\section{Conclusion}

We can conclude that this current study has shown the colossal effectiveness of Clitoria ternatea flower extracts against major dengue fever vectors during the early 4 th instar larval stages. Additionally, current findings showed the bioactive molecules even from crude extracts to be effective and may be developed as biolarvicides for Aedes mosquito vector control programs. Furthermore, this study also provided a baseline understanding for future research work on the field of applications of C. ternatea flower extracts which could be tested for their long-term effects applicable to other industries encompassing all aspects of human health.

\section{Data Availability}

The data used to support the findings of this study are available from the corresponding author upon request.

\section{Conflicts of Interest}

The authors declare no conflicts of interest.

\section{Acknowledgments}

The authors would like to acknowledge the Quest International University internal funds and also thank university staffs and research students who have contributed to this work.

\section{Supplementary Materials}

The NIST 08 library search for chemical compound structures and details. (Supplementary Materials)

\section{References}

[1] WHO, Update on the Dengue Situation in the Western Pacific Region: Northern Hemisphere Cambodia, World Health Organization, Geneva, Switzerland, 2020.

[2] R. Ravi, H. Zulkrnin, N. Shaida et al., "Evaluation of two different solvents for Azolla pinnata extracts on chemical compositions and larvicidal activity against Aedes albopictus (Diptera: Culicidae)," Journal of Chemistry, vol. 2018, Article ID 7453816, 8 pages, 2018.

[3] H. Zulkrnin, N. Shaida, N. N. Rozhan et al., "Larvicidal effectiveness of Azolla pinnata against Aedes aegypti (Diptera: Culicidae) with its effects on larval morphology and visualization of behavioural response," Journal of Parasitology Research, vol. 2018, Article ID 1383186, 5 pages, 2018.

[4] R. Ravi, N. S. H. Zulkrnin, N. N. Rozhan et al., "Chemical composition and larvicidal activities of Azolla pinnata extracts against Aedes (Diptera: Culicidae)," PLoS One, vol. 13, no. 11, Article ID e0206982, 2018.

[5] R. Ravi, I. H. Ishak, M. F. Mohd Amin, M. S. M. Rasat, M. A. Salam, and M. A. Mohd Amin, "Nano-synthesized silver particles and Azolla Pinnata extract Larvicidal effects against aedes aegypti (diptera: culicidae)," International Journal of Advanced Science and Technology, vol. 29, no. 4, pp. 3420-3427, 2020.

[6] A. Ghosh, N. Chowdhury, and G. Chandra, "Plant extracts as potential mosquito larvicides," The Indian Journal of Medical Research, vol. 135, no. 5, p. 581, 2012.

[7] G. Arumugam, P. Manjula, and N. Paari, "A review: anti diabetic medicinal plants used for diabetes mellitus," Journal of Acute Disease, vol. 2, no. 3, pp. 196-200, 2013.

[8] P. K. Mukherjee, V. Kumar, N. S. Kumar, and M. Heinrich, "The ayurvedic medicine Clitoria ternatea-from traditional use to scientific assessment," Journal of Ethnopharmacology, vol. 120, no. 3, pp. 291-301, 2008.

[9] N. Mathew, M. G. Anitha, T. S. L. Bala, S. M. Sivakumar, R. Narmadha, and M. Kalyanasundaram, "Larvicidal activity of Saraca indica, Nyctanthes arbor-tristis, and Clitoria ternatea extracts against three mosquito vector species," Parasitology Research, vol. 104, no. 5, pp. 1017-1025, 2009.

[10] S. Wong, L. Leong, and J. Williamkoh, "Antioxidant activities of aqueous extracts of selected plants," Food Chemistry, vol. 99, no. 4, pp. 775-783, 2006.

[11] S. Anand, A. Doss, and V. Nandagopalan, "Antibacterial studies on leaves of Clitoria ternatea linn.-a high potential medicinal plant," International Journal of Applied Biology and Pharmaceutical Technology, vol. 2, no. 3, pp. 453-456, 2011.

[12] T. K. Mathew and P. Benny, "Flowers with antibacterial property-a survey in Meenachil Taluk," Journal of Pharmaceutical, Chemical and Biological Sciences, vol. 4, no. 2, pp. 252-261, 2016.

[13] A. H. Ismail, A. N. Idris, M. M. Amina, A. S. Ibrahim, and S. A. Audu, "Phytochemical studies and thin layer chromatography of leaves and flower extracts of Senna siamea lam for possible biomedical applications," Journal of Pharmacognosy and Phytotherapy, vol. 7, no. 3, pp. 18-26, 2015.

[14] A. Divya, J. Anbumalarmathi, and S. Sharmili, "Phytochemical analysis, antimicrobial and antioxidant activity of Clitoria ternatea blue and white flowered leaves," Advances in Research, vol. 14, no. 5, pp. 1-13, 2018.

[15] J. Ferry and R. A. Larson, "A mixed solvent for rapid TLC analysis of phenolic compounds," Journal of Chromatographic Science, vol. 29, no. 11, pp. 476-477, 1991.

[16] M. Fu, Z. He, Y. Zhao, J. Yang, and L. Mao, “Antioxidant properties and involved compounds of daylily flowers in relation to maturity," Food Chemistry, vol. 114, no. 4, pp. 1192-1197, 2009.

[17] World Health Organization, Guidelines for Laboratory and Field Testing of Mosquito Larvicides, World Health Organization, Geneva, Switzerland, 2005.

[18] M. A. Principato, "Pupicidal and larvicidal composition," US20100310685A1, 2010.

[19] K. G. Koorse, S. Samraj, P. John et al., "Anthelmintic activity of fruit extract and fractions of Piper longum L. In vitro," Pharmacognosy Journal, vol. 10, no. 2, pp. 333-340, 2018.

[20] P. Bharali, Y. Gamo, A. K. Das, H. Tag, A. M. Baruah, and D. Kakati, "Phytochemical and biochemical study of four 
legume plants with detergent and anti-lice properties from the Eastern Himalayan region of India," Current Science, vol. 113, no. 7, p. 1434, Article ID 00113891, 2017.

[21] S. Vats and T. Gupta, "Evaluation of bioactive compounds and antioxidant potential of hydroethanolic extract of Moringa oleifera Lam. from Rajasthan, India," Physiology and Molecular Biology of Plants, vol. 23, no. 1, pp. 239-248, 2017.

[22] S. Fujita, T. Takayanagi, and S. Kato, "Agricultural chemicals formulation for rice paddy field, preparation thereof and the method for scattering the same," US6486095B1, 2002.

[23] S. H. Ahmed, "Evaluation of antioxidant and anti-mutagenic activity of naturally fortified honey with curcuma longa extract," International Journal of Biosciences (IJB), vol. 13, no. 1, pp. 248-256, 2018.

[24] M. Padmashree, R. Ashwathanarayana, and R. B. Raja Naika, "Antioxidant, cytotoxic and nutritive properties of Ipomoea staphylina Roem \& Schult. plant extracts with preliminary phytochemical and GCMS analysis," Asian Journal of Pharmacy and Pharmacology, vol. 4, no. 4, pp. 473-492, 2018.

[25] L. Cechovska, K. Cejpek, M. Konecny, and J. Velisek, "On the role of 2,3-dihydro-3,5-dihydroxy-6-methyl-(4H)-pyran-4one in antioxidant capacity of prunes," European Food Research and Technology, vol. 233, no. 3, pp. 367-376, 2011.

[26] J. Heeres, L. J. Backx, J. B. Thijssen, and A. G. Knaeps, "[[4-[4(4-phenyl-1-piperazinyl)phenoxymethyl]-1, 3-dioxolan-2-yl] methyl]-1h-imidazoles and 1h-1,2,4-triazoles having antimicrobial properties," PT78156A, 1988.

[27] S. Prabakaran, L. Ramu, S. Veerappan, B. Pemiah, and N. Kannappan, "Effect of different solvents on volatile and non-volatile constituents of red bell pepper (Capsicum annuum L.) and their in vitro antioxidant activity," Journal of Food Measurement and Characterization, vol. 11, no. 4, pp. 1531-1541, 2017.

[28] P. Van Kleef, "Insect control lighting device," US Patent 20180116196A1, 2019.

[29] J. D. Cleveland, "Herbicidal N-substituted-dithioamino and N-substituted-oxythioamino triazines," US Patent 3909237A, 1975.

[30] R. F. Henzell, R. H. Furneaux, and P. C. Tyler, “An evaluation of the herbicidal and plant growth regulatory activity of a novel class of carbohydrate-derived 6,8-dioxabicyclo[3.2.1] octanes," Pesticide Science, vol. 30, no. 1, pp. 59-66, 1990.

[31] C. Sangeetha, A. Krishnamoorthy, and D. Amirtham, "Antifungal bioactive compounds from Chinese caterpillar fungus (Ophiocordyceps sinensis (Berk.) GH Sung et al.) against plant pathogens," Madras Agricultural Journal, vol. 102, 2015.

[32] M. Nyamoita, Z. Mbwambo, B. Ochola, E. Innocent, W. Lwande, and A. Hassanali, "Chemical composition and evaluation of mosquito larvicidal activity of Vitex payoffs extracts against Anopheles gambiae Giles SS larvae," Spatula $D D$, vol. 3, no. 3, pp. 113-120, 2013.

[33] R. Pavela, "History, presence and perspective of using plant extracts as commercial botanical insecticides and farm products for protection against insects-a review," Plant Protection Science, vol. 52, no. 4, pp. 229-241, 2016.

[34] Z. Ullah, A. Ijaz, T. K. Mughal, and K. Zia, "Larvicidal activity of medicinal plant extracts against Culex quinquefasciatus Say. (Culicidae, Diptera)," International Journal of Mosquito Research, vol. 5, no. 2, pp. 47-51, 2018.

[35] B. B. Pereira and E. A. d. Oliveira, "Determinacao do potencial larvofago de Poecilia reticulata em condicoes domesticas de controle biologico," Cadernos Saude Coletiva, vol. 22, no. 3, pp. 241-245, 2014.
[36] A. Sunita, M. Sonam, and K. Ganesh, "Gas chromatographymass spectrometry analysis of an endangered medicinal plant, Sarcostemma viminale (L.) R. BR. From thar desert, Rajasthan (India)," Asian Journal of Pharmaceutical and Clinical Research, vol. 10, no. 9, p. 210, 2017.

[37] K. Bouabid, F. Lamchouri, H. Toufik, and M. E. A. Faouzi, "Phytochemical investigation, in vitro and in vivo antioxidant properties of aqueous and organic extracts of toxic plant: Atractylis gummifera L." Journal of Ethnopharmacology, vol. 253 , p. $112640,2020$. 